BMJ Open

Diabetes

Research

\& Care

\title{
Association between race/ethnicity and the risk of amputation of lower extremities among medicare beneficiaries with diabetic foot ulcers and diabetic foot infections
}

\author{
Tze-Woei Tan (10 , ${ }^{1}$ David G Armstrong, ${ }^{2}$ Kirsten C Concha-Moore, ${ }^{3}$ \\ David G Marrero, ${ }^{1}$ Wei Zhou, ${ }^{1}$ Elizabeth Calhoun, ${ }^{1}$ Ching-Yuan Chang, ${ }^{4}$ \\ Wei-Hsuan Lo-Ciganic ${ }^{4}$
}

To cite: Tan T-W, Armstrong DG, Concha-Moore KC, et al. Association between race/ ethnicity and the risk of amputation of lower extremities among medicare beneficiaries with diabetic foot ulcers and diabetic foot infections. BMJ Open Diab Res Care 2020;8:e001328. doi:10.1136/ bmjdrc-2020-001328

\section{- Additional material is} published online only. To view please visit the journal online (http://dx.doi.org/10.1136/ bmjdrc-2020-001328).

Received 3 March 2020 Revised 14 July 2020 Accepted 23 July 2020
Check for updates

(c) Author(s) (or their employer(s)) 2020. Re-use permitted under CC BY-NC. No commercial re-use. See rights and permissions. Published by BMJ.

For numbered affiliations see end of article.

Correspondence to Dr Tze-Woei Tan; ttan@surgery.arizona.edu

\section{ABSTRACT}

Introduction This study aimed to examine the association of race and ethnicity on the risk of lower extremity amputations among Medicare beneficiaries with diabetic foot ulcers (DFUs) and diabetic foot infections (DFIs).

Research design and methods A retrospective study included 2011-2015 data of a 5\% sample of fee-forservice Medicare beneficiaries with a newly diagnosed DFU and/or DFI. The primary outcome was the time to the first major amputation episode after a DFU and/or DFI were identified using the diagnosis and procedure codes. We used multivariable Cox proportional hazards models to estimate the risk of time to the first major amputation across races, adjusting for sociodemographic and health status factors. Adjusted hazard ratios (aHRs) with a $95 \% \mathrm{Cl}$ were reported. Results Among 92929 Medicare beneficiaries newly diagnosed with DFUs and/or DFIs, $77 \%$ were whites, 14.3\% African Americans (AAs), 3.3\% Hispanics, $0.7 \%$ Native Americans (NAs), and $4.0 \%$ were other races. The incidence rates of major amputation were 0.02 person-years for NAs, 0.02 person-years for AAs, 0.01 person-years for Hispanics, 0.01 personyears for other races, and 0.01 person-years for whites $(p<0.05)$. Multivariable analysis showed that AAs (aHR=1.9, 95\% Cl 1.7 to $2.2, p<0.0001)$ and NAs (aHR=1.8, 95\% Cl 1.3 to 2.6, $p=0.001$ ) were associated with an increased risk of major amputation compared with whites. Beneficiaries with DFUs and/ or DFls diagnosed by a podiatrist or primary care physician $(\mathrm{aHR}=0.7,95 \% \mathrm{Cl} 0.6$ to $0.8, \mathrm{p}<0.0001$, specialists as reference) or at an outpatient visit (aHR=0.3, 95\% Cl 0.3 to $0.3, p<0.0001$, inpatient stay as reference) were associated with a decreased risk of major amputation.

Conclusions Racial and ethnic disparities in the risk of lower extremity amputations appear to exist among fee-for-service Medicare beneficiaries with diabetic foot problems. AAs and NAs with DFUs and/ or DFIs were associated with an increased risk of major amputations compared with white Medicare beneficiaries.

\section{Significance of this study}

What is already known about this subject?

- The prevalence and incidence of diabetic foot ulcerations, peripheral artery disease, and lower extremity amputation differ by race and ethnicity. Although the relationship between race/ethnicity and the risk of peripheral arterial disease and amputation is well studied, there is conflicting evidence on the association of race/ethnicity and the risk of diabetes-related amputations.

What are the new findings?

- Racial and ethnic disparities in diabetes-related amputation and access to care exist among fee-forservice Medicare beneficiaries.

- Adjusting for socioeconomic factors and pre-existing medical comorbidities, African Americans and Native Americans experienced 1.8-1.9 times higher risk of major amputation for diabetic foot ulcerations and/ or diabetic foot infections than White Medicare beneficiaries.

- There were no significant difference in the risk of diabetes-related amputation for Hispanics and Whites.

- Race/ethnicity, the severity of presentation (including foot infection), and the location of the initial care of the diabetic foot problems independently affect the risk of major amputation.

How might these results change the focus of research or clinical practice?

- An improved access to a primary care physician or podiatrist to care for foot ulcers could help address the disparities for diabetes-related amputation among the racial/ethnic minorities.

\section{INTRODUCTION}

Diabetes has become one of the fastest growing chronic diseases diagnosed in the USA, affecting approximately 24.7 million 
people (9.7\% of adults) as of $2017 . .^{1}$ It is estimated that more than one-third of the US population will have diabetes by 2050 , and $34 \%$ of those will develop a diabetic foot ulcer (DFU) at some point in their lifetime. ${ }^{23}$ Foot ulceration is a lifelong problem for patients with diabetes. On average, two-thirds of DFUs take more than 1 year to heal, and the recurrence rate is estimated to be as high as $65 \%$ over 5 years. ${ }^{34}$ In 2010 , lower extremity amputations among patients with diabetes accounted for $60 \%$ of nontraumatic amputations in the USA. ${ }^{5}$ DFUs and diabetic foot infections (DFIs) are the leading causes of amputations. Mortality rates, physical function, and quality of life are significantly worse in patients with DFUs/DFIs and after amputations. ${ }^{6-10}$

The prevalence and incidence of diabetes, DFUs, DFIs, and amputations differ by race and ethnicity. ${ }^{11}{ }^{12}$ African Americans (AAs), Hispanics, and Native Americans (NAs) have a higher prevalence of diabetes than nonHispanic whites (hereafter referred to as "whites"). ${ }^{11} 12$ Consequently, the incidence of DFUs and amputations are disproportionately higher in AAs, Hispanics, and NAs. ${ }^{12}$ In 2008, the incidence of DFUs among Medicare beneficiaries was $6.0 \%$ for whites, $6.3 \%$ for AAs, $6.4 \%$ for Hispanics, and $7.0 \%$ for NAs. ${ }^{11}$ The incidence of diabetes-related amputations in AAs and other minorities was more than double that of whites. ${ }^{11}$

Health disparities or health inequities have been well documented for diabetes, peripheral arterial disease (PAD), and amputations. ${ }^{13-15}$ More specifically, the relationship between race/ethnicity and $\mathrm{PAD}$ and amputation has been well studied and confirmed through consistent findings, but there is conflicting evidence on the effect of race/ethnicity on diabetes related amputations. ${ }^{16}$ While a few studies found approximately a 1.52.0-fold increased risk of amputation among AAs and Hispanics with diabetes ${ }^{17-20}$ other studies did not find any differences in the risk of amputation between whites and minority races. ${ }^{21} 22$ Additionally, socioeconomic and insurance statuses are the main contributors to the elevated risk of amputation among racial and ethnic minorities. ${ }^{23-26}$ However, the majority of previous studies evaluating disparities in amputation among patients with diabetes did not adjust for socioeconomic background or insurance status. Hence, we sought to examine the association between race/ethnicity (whites, AAs, Hispanics, NAs, and other races) and the risk of amputation of lower extremities among Medicare beneficiaries with DFUs and/or DFIs.

\section{METHODS}

Data sources

This study used Medicare administrative claims data of a 5\% national representative sample from 2011 to 2015 (approximately 3.6 million unique beneficiaries). Medicare is the US governmental health insurance program provided to individuals aged $\geq 65$ years and those aged $<65$ years with certain disabilities or end-stage renal diseases (ESRDs).$^{27}$ The data files included master beneficiary summary files (MBSF) with enrollment and eligibility information; claims for inpatient, outpatient, and professional services as well as skilled nursing facilities; and Part D Events files. The University of Arizona Institutional Review Board approved this study.

\section{Study design and cohort}

This retrospective cohort study included fee-for-service beneficiaries with diabetes and a newly diagnosed DFU and/or DFI from 2011 to 2014 using the International Classification of Diseases codes (see online supplementary table 1 for International classification of diseases, 9th revision, clinical modification (ICD-9-CM)/ICD-10-CM codes) ${ }^{28}$ We restricted the analytical sample to beneficiaries with at least one medical claim with a diabetes diagnosis, and at least one medical claim with a DFU and/or DFI diagnosis. DFU and DFI include ulcer of lower limbs, ulcer of the heel and midfoot, ulcer of other parts of the foot, chronic ulcer of other specified sites, chronic ulcer of unspecified sites, osteomyelitis, cellulitis and abscess of the toe, cellulitis and abscess of the foot (except toes), gangrene, or gas gangrene. The method has been used and verified by other studies. ${ }^{28}{ }^{29}$ The index date was the earliest date of the patient's diagnosis of a DFU and/or DFI during the study period.

We excluded beneficiaries who (1) were non-US residents; (2) received hospice services during the study period (table 1); and, (3) did not have continuous enrollment in Parts A, B, and D for at least 6 months before the index date or the index date was after $1 / 1 / 2015$ (figure 1). Each beneficiary was followed up until one of the following events: a major amputation for lower extremity, death, enrollment into Medicare Advantage plans, or the end of the study period $(12 / 31 / 2015)$.

\section{Primary outcome: time to first major amputation for lower extremities}

Our primary outcome was time to the first major amputation episode for lower extremities, including both above-knee amputation (AKA) and below-knee amputation (BKA) after the index diagnosis of a DFU or DFI. We used the ICD-9 Procedure codes and the Current Procedure Terminology codes to identify AKA (V49.76, 27590-27592, 27596, and 27598) and BKA (V49.75, 27880-27 882, 27886, 27888 , and 27889).

\section{Main independent variable and covariates}

Based on the race/ethnicity information in the MBSF dataset, we categorized beneficiaries into five racial/ ethnic groups (ie, our main independent variable): whites, AAs, Hispanics, NAs, and other races (including Asians and other or unknown races).

We also considered several sociodemographic and health status covariates in the analyses. Sociodemographic factors included age, gender (male vs female), disability status, receipt of low-income subsidy, and type of resided county (metropolitan, non-metropolitan, 
Table 1 Characteristics of the study population stratified by amputation status

\begin{tabular}{|c|c|c|c|c|}
\hline & $\begin{array}{l}\text { Total } \\
(\mathrm{n}=92929)\end{array}$ & $\begin{array}{l}\text { No amputation } \\
(n=91203)\end{array}$ & $\begin{array}{l}\text { Major amputation } \\
(n=1726)\end{array}$ & $P$ value \\
\hline \multicolumn{5}{|l|}{ Demographics } \\
\hline Age, mean (SD) & 71.87 (11.86) & 71.96 (11.85) & $67.06(12.51)$ & $<0.0001$ \\
\hline \multicolumn{5}{|l|}{ Age group } \\
\hline$<65$ years & 23212 (24.98) & 22477 (24.65) & 735 (42.58) & $<0.0001$ \\
\hline$\geq 65$ years & 69717 (75.02) & 68726 (75.35) & $991(57.42)$ & \\
\hline \multicolumn{5}{|l|}{ Gender } \\
\hline Male & 42508 (45.74) & 41423 (45.42) & $1085(62.86)$ & $<0.0001$ \\
\hline Female & $50421(54.26)$ & $49780(54.58)$ & $641(37.14)$ & \\
\hline \multicolumn{5}{|l|}{ Socioeconomic factors } \\
\hline Disability & $28683(30.87)$ & 27814 (30.50) & $869(50.35)$ & $<0.0001$ \\
\hline Low income subsidy & $59063(63.56)$ & 57802 (63.38) & $1261(73.06)$ & $<0.0001$ \\
\hline \multicolumn{5}{|l|}{ Country residence } \\
\hline Metropolitan & 76248 (82.05) & 74958 (82.19) & $1290(74.74)$ & $<0.0001$ \\
\hline Non-metropolitan & $16534(17.79)$ & $16100(17.65)$ & $434(25.14)$ & \\
\hline Unknown & $147(0.16)$ & $145(0.16)$ & $2(1.36)$ & \\
\hline \multicolumn{5}{|l|}{ Median income } \\
\hline Q1 & 23353 (25.13) & 22767 (24.96) & $586(33.95)$ & $<0.0001$ \\
\hline Q2 & $23343(25.12)$ & 22872 (25.08) & $471(27.29)$ & \\
\hline Q3 & $23063(24.82)$ & $22688(24.88)$ & 375 (21.73) & \\
\hline Q4 & $23170(24.93)$ & $22876(25.08)$ & $294(17.03)$ & \\
\hline \multicolumn{5}{|l|}{ Poverty } \\
\hline$<20 \%$ & 73137 (78.70) & 71889 (78.82) & $1248(72.31)$ & $<0.0001$ \\
\hline$\geq 20 \%$ & $19792(21.30)$ & $19314(21.18)$ & 478 (27.69) & \\
\hline \multicolumn{5}{|l|}{ Medical history } \\
\hline ESRD & $2448(2.63)$ & $2192(2.40)$ & $256(14.83)$ & $<0.0001$ \\
\hline PAD & $49774(53.56)$ & 48307 (52.97) & $1467(84.99)$ & $<0.0001$ \\
\hline Insulin & $14672(15.79)$ & $14131(15.49)$ & $541(31.34)$ & $<0.0001$ \\
\hline $\begin{array}{l}\text { Elixhauser comorbidity index, mean } \\
\text { (SD) (range 0-29) }\end{array}$ & $3.87(2.88)$ & $3.85(2.87)$ & $4.98(3.35)$ & $<0.0001$ \\
\hline DCSI, mean (SD) (range 0-13) & $2.12(1.35)$ & $2.11(1.35)$ & $3.06(1.39)$ & $<0.0001$ \\
\hline \multicolumn{5}{|l|}{ Index diagnosis } \\
\hline DFU & 29696 (31.96) & 28930 (31.72) & $766(44.38)$ & $<0.0001$ \\
\hline DFI & $63233(68.04)$ & $62273(68.28)$ & $960(55.62)$ & $<0.0001$ \\
\hline \multicolumn{5}{|l|}{ Specialty for DFU/DFI diagnosis } \\
\hline Primary care & $10806(11.63)$ & $10681(11.71)$ & $125(7.24)$ & $<0.0001$ \\
\hline Podiatry & 20625 (22.19) & $20439(22.41)$ & $186(10.78)$ & \\
\hline Specialist & $61498(66.18)$ & $60083(65.88)$ & $1415(81.98)$ & \\
\hline \multicolumn{5}{|l|}{ Place of DFU/DFI diagnosis } \\
\hline Hospital & $6814(7.33)$ & $6350(6.96)$ & $464(26.88)$ & $<0.0001$ \\
\hline Outpatient & $49979(53.78)$ & $49329(54.09)$ & $650(37.66)$ & \\
\hline ED & 1845 (1.99) & $1757(1.93)$ & $88(5.10)$ & \\
\hline Home health agency & $606(0.65)$ & $598(0.66)$ & $8(0.46)$ & \\
\hline Skilled nursing facility & $3546(3.82)$ & $3479(3.81)$ & $67(3.88)$ & \\
\hline Other & 30139 (32.43) & $29690(32.55)$ & $449(26.01)$ & \\
\hline
\end{tabular}

Continued 
Table 1 Continued

\begin{tabular}{|c|c|c|c|c|}
\hline & $\begin{array}{l}\text { Total } \\
(n=92929)\end{array}$ & $\begin{array}{l}\text { No amputation } \\
(\mathrm{n}=91203)\end{array}$ & $\begin{array}{l}\text { Major amputation } \\
(n=1726)\end{array}$ & $P$ value \\
\hline $\begin{array}{l}\text { Early PCP follow-up ( } 30 \text { days after } \\
\text { diagnosis) }\end{array}$ & $45727(49.21)$ & $44639(48.94)$ & $1088(63.04)$ & $<0.0001$ \\
\hline Revascularization within 12 months & $8178(8.80)$ & $7288(7.99)$ & $890(51.56)$ & $<0.0001$ \\
\hline \multicolumn{5}{|l|}{ Healthcare utilization after diagnosis } \\
\hline ED visits per person, mean (SD) & $0.63(1.36)$ & $0.63(1.35)$ & $1.09(1.73)$ & $<0.0001$ \\
\hline Outpatient visits per person, mean (SD) & $3.19(5.91)$ & $3.22(5.93)$ & $1.14(4.45)$ & $<0.0001$ \\
\hline $\begin{array}{l}\text { Inpatient hospital stay per person, mean } \\
\text { (SD) }\end{array}$ & $16.06(29.84)$ & $15.70(29.50)$ & $35.08(44.16)$ & $<0.0001$ \\
\hline
\end{tabular}

Values are reported as number (\%) unless otherwise specified.

DCSI, Diabetes Complications Severity Index; DFI, diabetic foot infection; DFU, diabetic foot ulcer; ED, emergency room; ESRD, end-stage renal disease; PAD, peripheral artery disease; PCP, primary care physician; $Q$, quartile.

and unknown). We linked the data to the Area Health Resources Files to obtain information on median household income (divided into quartiles), and percentage of individuals residing below the federal poverty level at the specific residential area $(<20 \%$ vs $\geq 20 \%)$ based on the individual's resided zip code.

Several health status covariates measured in the 6 months prior to the index DFU/DFI diagnosis included ESRD, PAD, receiving insulin therapy, the Elixhauser comorbidity index (range 0-29, excluding diabetes categories), and the Diabetes Complication Severity Index (DCSI) (range 0-13). ${ }^{30-32}$

We also included the specialty of the provider (primary care physician (PCP), podiatry, and specialist) and type of service settings (inpatient, outpatient, emergency department (ED), home health agency, skilled nursing facility, and others) regarding the initial DFU and/or DFI diagnosis. ${ }^{14}$ The utilization of healthcare resources included a PCP follow-up visit 30 days after the index diagnosis, open surgery or a percutaneous procedure for revascularization of lower extremities within a year after the diagnosis of DFU and/or DFI, number of ED visits within a year (per person), outpatient visits within a year (per person), and inpatient hospital stay per person (average within a year) after the index diagnosis. ${ }^{14}$

\section{Statistical analysis}

The characteristics of beneficiaries with DFUs/DFIs in each racial group are described as a mean and SD, or a median and IQR, for continuous variables as well as a frequency and a percentage for categorical variables. The analysis of variance and $\chi^{2}$ test were used to compare continuous and categorical variables among the racial/ ethnic groups, respectively. We used Kaplan-Meier (KM) survival curves to describe the time to first major amputations across racial groups during the study period. Multivariable Cox proportional hazard models were performed to estimate the risk of major amputation for

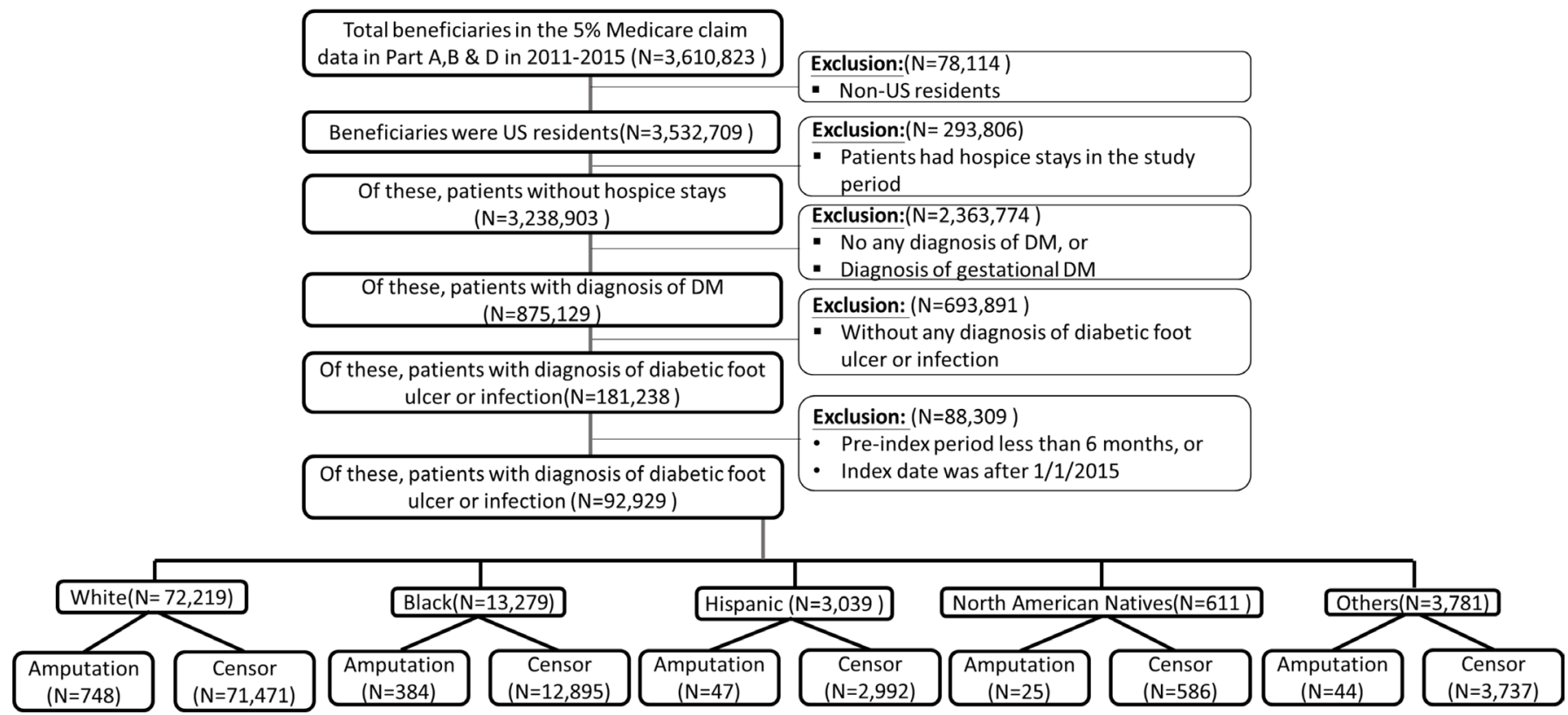

Figure 1 Flowchart of the study population. 
lower extremities across racial/ethnic groups, adjusting for the covariates described above. The adjusted hazard ratio (aHR) with a 95\% CI was reported. $\mathrm{P}<0.05$ (twotailed) was considered as statistically significant in the study. All the analyses were performed using SAS V.9.4 (SAS, Cary, North Carolina, USA).

\section{RESULTS}

Among the 92929 Medicare beneficiaries with a DFU/ DFI, $72219(77.7 \%)$ were whites, $13279(14.3 \%)$ were AAs, 3039 (3.3\%) were Hispanics, $611(0.7 \%)$ were NAs, and $3781(4.0 \%)$ were other races. The median follow-up for the study cohort was 911 days ( $\mathrm{IQR}=650$ days). During the study period, 1726 beneficiaries (1.9\%) underwent a major amputation.

As shown in table 1, compared with beneficiaries with DFUs/DFIs who did not have a major amputation, those who did have a major amputation for lower extremities during the study period were more likely to be younger $(<65$ years: $42.6 \%$ vs $24.7 \%)$, male $(62.9 \%$ vs $45.4 \%)$, have ESRD ( $14.8 \%$ vs $2.4 \%)$, PAD $(85.0 \%$ vs $53.0 \%)$, and more severe diabetes-related complications as determined by the DCSI (3.06 vs 2.11), and use insulin (31.3\% vs $15.5 \%)$. Those who had a major amputation were also more likely to have a disability $(59.4 \%$ vs $30.5 \%)$, receive a low-income subsidy ( $73.1 \%$ vs $63.4 \%)$, live in non-metropolitan area $(25.1 \%$ vs $17.7 \%)$, and live in areas with more than a $20 \%$ poverty level $(27.7 \%$ vs $21.2 \%)$. In addition, they were more likely to be seen by a specialist at the initial diagnosis $(82.0 \%$ vs $65.9 \%)$, but less likely to be seen by a PCP $(7.2 \%$ vs $11.7 \%)$ or a podiatrist $(10.8 \%$ vs $22.4 \%)$. Compared with those who did not have a major amputation, those who did had significantly more ED visits per person (mean $=1.1 \pm 1.7$ visits vs $0.6 \pm 1.4$ visits), longer inpatient stay per person (44.2 days vs 29.5 days), and fewer outpatient visits (4.5 visits vs 5.9 visits) within a year after the diagnosis of a DFU and/or DFI.

\section{Unadjusted association between racial groups and risk of major amputation for lower extremities}

In unadjusted analyses (table 2), compared with white beneficiaries, the risks of major amputation for lower extremities were significantly higher for NAs $(\mathrm{HR}=3.62$, $95 \% \mathrm{CI}=2.53$ to $5.17, \mathrm{p}<0.0001)$, AAs $(\mathrm{HR}=2.65,95 \%$ $\mathrm{CI}=2.38$ to $2.94, \mathrm{p}<0.0001)$, and Hispanic $(\mathrm{HR}=1.41$, $95 \% \mathrm{CI}=1.10$ to $1.82, \mathrm{p}=0.0007)$ beneficiaries. As shown in figure 2, the unadjusted KM survival analysis demonstrated that the percentages of major amputation events were higher for NAs (5.1\%), AAs (3.8\%), Hispanics $(2.1 \%)$, and Others $(1.5 \%)$ than whites with DFUs/ DFIs $(1.5 \%)$. Minority beneficiaries, including Hispanics $(89.5 \%)$, others $(86.9 \%)$, and AAs $(85.2 \%)$, were more likely than whites were $(81.0 \%, \mathrm{p}<0.0001)$ to have a DFI as an index diagnosis.
Adjusted association of race and ethnicity with major amputation for lower extremities

In multivariable analyses (table 3), the risk of major amputation was significantly higher for AAs $(\mathrm{aHR}=1.92$, $95 \%=$ CI 1.71 to $2.15, \mathrm{p} \leq 0.0001)$ and NAs $(\mathrm{aHR}=1.81,95 \%$ $\mathrm{CI}=1.26$ to $2.61, \mathrm{p}=0.001$ ) compared with white beneficiaries. There was no difference in the risk of major amputation for lower extremities between Hispanics $(\mathrm{aHR}=1.18$, $95 \% \mathrm{CI}=0.88$ to $1.60, \mathrm{p}=0.27)$ and other races (aHR 1.18 , $95 \%$ CI 0.86 to $1.60, \mathrm{p}=0.31$ ) compared with white beneficiaries with DFUs/DFIs.

\section{Factors associated with major amputation for lower extremities}

Factors associated with an increased risk of major amputation for lower extremities included male gender (aHR $1.79,95 \%$ CI 1.62 to 1.98 ), medical comorbidities that included PAD (aHR 2.95, 95\% CI 2.55 to 3.41 ) and ESRD (aHR 2.77, 95\% CI 2.36 to 3.22)], a higher DCSI (aHR $1.19,95 \%$ CI 1.14 to 1.24 ), and use of insulin (aHR 1.62, $95 \%$ CI 1.45 to 1.81 ) (all $\mathrm{p}<0.0001)$.

Disabled individuals (aHR 1.31, 95\% CI 1.16 to 1.47 ), residents of non-metropolitan counties (HR=1.40, $95 \%$ CI 1.23 to 1.58 ), and low-income subsidy recipients (aHR 2.11, 95\% CI 1.66 to 2.69) (all p<0.0001) had a significantly higher risk of major amputation. A higher median income was associated with a lower risk of amputation (Q1: reference; Q2: aHR 0.88, 95\% CI 0.76 to 1.03 , $\mathrm{p}=0.11$; $\mathrm{Q} 3$ : aHR $0.75,95 \%$ CI 0.63 to $0.90, \mathrm{p}=0.001 ; \mathrm{Q} 4$ : aHR $0.69,95 \%$ CI 0.57 to $0.83, p=0.0001$ ).

Beneficiaries whose index DFUs/DFIs were diagnosed by a specialist were associated with an increased risk of major amputation for lower extremities (aHR 1.46, $95 \%$ CI 1.20 to $1.76, \mathrm{p}=0.0001$ ) than those with index DFUs/DFIs who were diagnosed by a PCP or a podiatrist. When the comparison was made with beneficiaries who had the index diagnosis made during an outpatient visit, the risk of amputation appeared to be higher for patients who had a diagnosis made during an inpatient admission or ED visit.

\section{DISCUSSION}

Our retrospective cohort study is one of the largest population-based studies demonstrating that racial/ ethnic disparities exist regarding the risk of major amputation for lower extremities among fee-for-service Medicare beneficiaries newly diagnosed with a DFU/DFI. AAs and NAs experienced a higher risk of major amputation compared with white beneficiaries after developing a DFU or DFI. Minorities had more significant medical comorbidities on presentation and were more likely to present with a DFI than whites were. Healthcare resource utilization for DFU/DFI care, including outpatient visits and hospital admissions, was significantly higher for minority than for white beneficiaries.

Compared with white beneficiaries, our adjusted analysis showed a 1.8-1.9 times higher risk of major 
Table 2 Characteristics of study population stratified by racial and ethnic groups

\begin{tabular}{|c|c|c|c|c|c|}
\hline & $\begin{array}{l}\text { White } \\
(\mathrm{n}=72219)\end{array}$ & $\begin{array}{l}\text { African American } \\
(n=13279)\end{array}$ & $\begin{array}{l}\text { Hispanic } \\
(\mathrm{n}=3039)\end{array}$ & $\begin{array}{l}\text { Native American } \\
(\mathrm{n}=611)\end{array}$ & $\begin{array}{l}\text { Other } \\
(\mathrm{n}=3781)\end{array}$ \\
\hline \multicolumn{6}{|l|}{ Demographics } \\
\hline Age, mean (SD) & $72.6(11.5)$ & $68.6(12.8)$ & $69.7(14.1)$ & $66.6(12.4)$ & 71.7 (11.4) \\
\hline \multicolumn{6}{|l|}{ Age group } \\
\hline$<65$ years & $16140(22.4)$ & 4907 (37.0) & 992 (32.6) & $250(40.9)$ & $923(24.4)$ \\
\hline$\geq 65$ years & $56079(77.7)$ & $8372(63.1)$ & $3264(67.4)$ & $361(59.1)$ & 2858 (75.6) \\
\hline \multicolumn{6}{|l|}{ Gender } \\
\hline Male & $33673(46.6)$ & $5310(40.0)$ & $1386(45.6)$ & $269(44.0)$ & $1870(49.5)$ \\
\hline Female & $38546(53.4)$ & 7969 (60.0) & $1653(54.4)$ & $342(56.0)$ & $1911(50.5)$ \\
\hline \multicolumn{6}{|l|}{ Socioeconomic factor } \\
\hline Disability & $20204(28.0)$ & 6188 (46.6) & 1155 (38.0) & $313(51.2)$ & $823(21.8)$ \\
\hline Low income subsidy & $42543(58.9)$ & $10377(78.2)$ & 2741 (90.2) & $506(82.8)$ & 2896 (76.6) \\
\hline \multicolumn{6}{|l|}{ Country residence } \\
\hline Metropolitan & $57807(80.0)$ & $11717(88.2)$ & 2840 (93.5) & $298(48.8)$ & $3586(94.8)$ \\
\hline Non-metropolitan & $14312(19.8)$ & $1542(11.6)$ & $188(6.2)$ & 309 (50.9) & $183(4.9)$ \\
\hline Unknown & $100(0.1)$ & $20(0.2)$ & $11(0.4)$ & $4(0.7)$ & $12(0.3)$ \\
\hline \multicolumn{6}{|l|}{ Median income } \\
\hline Q1 & $17480(24.2)$ & 4267 (32.1) & 996 (32.8) & $287(47.0)$ & $323(8.5)$ \\
\hline Q2 & $18744(26.0)$ & $3279(24.7)$ & $472(15.5)$ & $180(29.5)$ & 668 (17.7) \\
\hline Q3 & $17481(24.2)$ & $3142(23.7)$ & $985(32.4)$ & $80(13.1)$ & $1375(36.4)$ \\
\hline Q4 & $18514(25.6)$ & 2591 (19.5) & $586(19.3)$ & $64(10.5)$ & $1415(37.4)$ \\
\hline \multicolumn{6}{|l|}{ Poverty } \\
\hline$<20 \%$ & $58894(81.6)$ & $8752(65.9)$ & 1891 (62.2) & $349(57.1)$ & 3251 (86.0) \\
\hline$\geq 20 \%$ & $13325(18.5)$ & 4527 (34.1) & $1148(37.8)$ & 262 (42.9) & $530(14.0)$ \\
\hline Low income subsidy & $42543(58.9)$ & $10377(78.2)$ & 2741 (90.2) & $506(82.8)$ & 2896 (76.6) \\
\hline \multicolumn{6}{|l|}{ Medical history } \\
\hline ESRD & $1191(1.7)$ & $843(6.4)$ & $177(5.8)$ & $61(10)$ & $176(4.7)$ \\
\hline PAD & $38105(52.8)$ & $7943(59.8)$ & $1658(54.6)$ & $352(57.6)$ & $1716(45.4)$ \\
\hline Insulin & $10328(14.3)$ & $2835(21.4)$ & $738(24.3)$ & $157(25.7)$ & $614(16.2)$ \\
\hline $\begin{array}{l}\text { Elixhauser comorbidity } \\
\text { index, mean (SD) (range } \\
0-29 \text { ) }\end{array}$ & $3.8(2.8)$ & $4.4(3.2)$ & $3.9(2.8)$ & $4.0(3.0)$ & $3.5(2.7)$ \\
\hline $\begin{array}{l}\text { DCSI, mean (SD) (range } \\
0-13 \text { ) }\end{array}$ & $2.1(1.3)$ & $2.4(1.4)$ & $2.3(1.4)$ & $2.2(1.5)$ & $2.1(1.3)$ \\
\hline \multicolumn{6}{|l|}{ Index diagnosis } \\
\hline DFU & $13726(19.0)$ & $1963(14.8)$ & $319(10.5)$ & $119(19.5)$ & $496(13.1)$ \\
\hline DFI & $58493(81.0)$ & $11316(85.2)$ & $2720(89.5)$ & $492(80.5)$ & 3285 (86.9) \\
\hline \multicolumn{6}{|l|}{$\begin{array}{l}\text { Specialty for DFU/DFI } \\
\text { diagnosis }\end{array}$} \\
\hline Primary care & $8367(11.6)$ & $1406(10.6)$ & $389(12.8)$ & $95(15.6)$ & $549(14.5)$ \\
\hline Podiatry & $16405(22.7)$ & $2748(20.7)$ & $628(20.7)$ & $69(11.3)$ & $775(20.5)$ \\
\hline Specialist & $47447(65.7)$ & $9125(68.7)$ & $2022(66.5)$ & $447(73.2)$ & $2457(65)$ \\
\hline \multicolumn{6}{|c|}{ Place of DFU/DFI diagnosis } \\
\hline Hospital & $4098(5.7)$ & $1041(7.8)$ & $174(5.7)$ & $57(9.3)$ & $172(4.6)$ \\
\hline Outpatient & $10632(14.7)$ & 1797 (13.5) & $328(10.8)$ & 253 (41.4) & 370 (9.8) \\
\hline ED & 809 (1.1) & 213 (1.6) & $44(1.5)$ & $17(2.8)$ & $42(1.1)$ \\
\hline
\end{tabular}


Table 2 Continued

\begin{tabular}{|c|c|c|c|c|c|}
\hline & $\begin{array}{l}\text { White } \\
(n=72219)\end{array}$ & $\begin{array}{l}\text { African American } \\
(n=13279)\end{array}$ & $\begin{array}{l}\text { Hispanic } \\
(\mathrm{n}=3039)\end{array}$ & $\begin{array}{l}\text { Native American } \\
(\mathrm{n}=611)\end{array}$ & $\begin{array}{l}\text { Other } \\
(n=3781)\end{array}$ \\
\hline Home health agency & $476(0.7)$ & $85(0.6)$ & $26(0.9)$ & $1(0.2)$ & $18(0.5)$ \\
\hline Skilled nursing facility & $1628(2.3)$ & $363(2.7)$ & $51(1.7)$ & $8(1.3)$ & $82(2.2)$ \\
\hline Other & $54576(75.6)$ & $9780(73.7)$ & 2416 (79.5) & $275(45.0)$ & 3097 (81.9) \\
\hline $\begin{array}{l}\text { Early PCP follow-up ( } 30 \\
\text { days after diagnosis) }\end{array}$ & $35242(48.8)$ & $6742(50.8)$ & $1523(50.1)$ & $328(53.7)$ & $1892(50.0)$ \\
\hline $\begin{array}{l}\text { Revascularization within } 12 \\
\text { months }\end{array}$ & $5499(7.6)$ & 1899 (14.3) & $345(11.4)$ & $101(16.5)$ & $334(8.8)$ \\
\hline \multicolumn{6}{|l|}{$\begin{array}{l}\text { Healthcare utilization after } \\
\text { DFU/DFI diagnosis }\end{array}$} \\
\hline $\begin{array}{l}\text { ED visits per person, } \\
\text { mean (SD) }\end{array}$ & $0.02(0.2)$ & $0.03(0.2)$ & $0.03(0.2)$ & $0.03(0.2)$ & $0.01(0.1)$ \\
\hline $\begin{array}{l}\text { Outpatient visits per } \\
\text { person, mean (SD) }\end{array}$ & 1.59 & 2.25 & 2.39 & 2.23 & 1 \\
\hline $\begin{array}{l}\text { Inpatient hospital stay per } \\
\text { person, mean (SD) }\end{array}$ & $13.93(27.6)$ & $19.26(28.7)$ & $15.4(21.6)$ & 15.65 (26.95) & $15.65(27.0)$ \\
\hline $\begin{array}{l}\text { Number of major } \\
\text { amputations }\end{array}$ & $1068(1.5)$ & $507(3.8)$ & $64(2.1)$ & $31(5.1)$ & $56(1.5)$ \\
\hline $\begin{array}{l}\text { Unadjusted risks of major } \\
\text { amputation }\end{array}$ & Reference & $\begin{array}{l}\mathrm{HR}=2.65,95 \% \\
\mathrm{Cl}=2.38 \text { to } 2.94 \\
\mathrm{p}<0.0001\end{array}$ & $\begin{array}{l}\mathrm{HR}=1.41,95 \% \\
\mathrm{Cl}=1.10 \text { to } 1.82 \\
\mathrm{p}=0.0007\end{array}$ & $\begin{array}{l}\mathrm{HR}=3.62,95 \% \\
\mathrm{Cl}=2.53 \text { to } 5.17 \\
\mathrm{p}<0.0001\end{array}$ & $\begin{array}{l}\mathrm{HR}-1.00,95 \% \\
\mathrm{Cl}=0.77 \text { to } 1.31, \\
\mathrm{p}=0.98\end{array}$ \\
\hline
\end{tabular}

Values are reported as number (\%) unless otherwise specified.

DCSI, Diabetes Complications Severity Index; DFI, diabetic foot infection; DFU, diabetic foot ulcer; ED, emergency room; ESRD, end-stage renal disease; PAD, peripheral artery disease; $P C P$, primary care physician; $Q$, quartile.

amputation for DFU/DFI among AAs and NAs, but no significant difference in the risk of major amputation for Hispanics. Although racial disparity in amputation is better documented in $\mathrm{PAD}$, prior studies examining the association of racial/ethnic disparities in amputation for lower extremities in diabetes are inconsistent or inconclusive. A recent study by our group reported

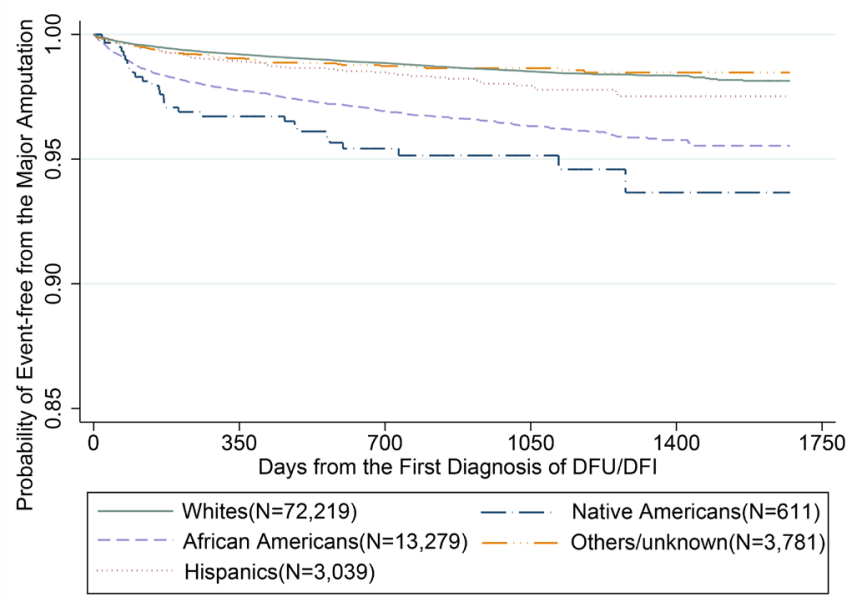

Figure 2 Kaplan-Meier survival curve for major amputation (online supplementary table 1). ICD-9-CM codes. DFI, diabetic foot infection; DFU, diabetic foot ulcer; ICD-CM, International classification of diseases, 9th revision, clinical modification. a considerably higher risk of major amputations among minorities admitted with DFIs than whites. ${ }^{29}$ Studies by Lavery $e t$ al and Resnick $e t$ al also described an increased risk of amputation for AAs compared with whites, while Karter et al reported no difference in the risk of amputation among AAs and whites as well as among AAs and Hispanics. ${ }^{17} 1822$ A different study evaluating Medicare beneficiaries with ESRD and diabetes reported that the risk of amputation was highest in whites compared with $\mathrm{AA}$ and other minorities. ${ }^{21}$ The inconsistent findings could be due to different study populations. ${ }^{17} 18212229$

Possible explanations for the higher risk of amputation observed in minorities include results shaped by more advanced presentation of a diabetic foot problem, the presence of more severe comorbidities, and the lack of access to limb salvage services. Similar to others, our study suggests minorities at risk of major amputation for lower extremities were more likely to have DFI and PAD on presentation. ${ }^{24}{ }^{33}$ In addition, DFI and progressive gangrene are the leading causes of major amputation in patients with diabetes. ${ }^{6435}$ Insurance status, a surrogate reflecting access to medical care, is one of the most significant contributors of disparities in lower extremity amputation. ${ }^{23}{ }^{36}$ Major amputations are more likely to be performed on patients without any, or with suboptimal, health insurance coverage, such as Medicaid. ${ }^{36} 37$ It is, however, unclear whether the same disparities exist among the insured population with presumably better 
Table 3 Cox proportional hazard models for major amputation

\begin{tabular}{llll}
\hline \multicolumn{4}{l}{ Adjusted HR } \\
\hline $\begin{array}{l}\text { Race/Ethnicity } \\
\text { White }\end{array}$ & Reference & P value \\
\hline African American & 1.92 & 1.71 to 2.15 & $<0.0001$ \\
\hline Hispanic & 1.09 & 0.84 to 1.41 & 0.6 \\
\hline Native American & 1.81 & 1.26 to 2.61 & 0.001 \\
\hline Other & 1.02 & 0.78 to 1.34 & 0.88 \\
\hline Age & 1.01 & 0.99 to 1.01 & 0.33 \\
\hline Male gender & 1.79 & 1.62 to 1.98 & $<0.0001$ \\
\hline Disability & 1.31 & 1.16 to 1.47 & $<0.0001$ \\
\hline County residence & & & \\
\hline Metropolitan & Reference & & \\
\hline Non-metropolitan & 1.4 & 1.23 to 1.58 & $<0.0001$ \\
\hline Median income & & & \\
\hline Q1 & Reference & & \\
\hline Q2 & 0.88 & 0.76 to 1.03 & 0.11 \\
\hline Q3 & 0.75 & 0.63 to 0.90 & 0.001 \\
\hline Q4 & 0.69 & 0.57 to 0.83 & 0.0001 \\
\hline
\end{tabular}

Poverty

\begin{tabular}{|c|c|c|c|}
\hline$<20 \%$ & Reference & & \\
\hline$\geq 20 \%$ & 0.89 & 0.76 to 1.03 & 0.1 \\
\hline Low income subsidy & 1.34 & 1.19 to 1.51 & $<0.0001$ \\
\hline PAD & 2.95 & 2.55 to 3.41 & $<0.0001$ \\
\hline ESRD & 2.77 & 2.36 to 3.22 & $<0.0001$ \\
\hline $\begin{array}{l}\text { Elixhauser Comorbidity } \\
\text { Index }\end{array}$ & 1.01 & 0.99 to 1.02 & 0.64 \\
\hline DCSI & 1.19 & 1.14 to 1.24 & $<0.0001$ \\
\hline Insulin & 1.62 & 1.45 to 1.81 & $<0.0001$ \\
\hline \multicolumn{4}{|l|}{ Specialty for diagnosis } \\
\hline Primary care & Reference & & \\
\hline Podiatry & 0.89 & 0.71 to 1.12 & 0.31 \\
\hline Specialist & 1.46 & 1.20 to 1.76 & 0.0001 \\
\hline \multicolumn{4}{|l|}{ Place of diagnosis } \\
\hline Hospital & Reference & & \\
\hline $\begin{array}{l}\text { Emergency } \\
\text { department }\end{array}$ & 0.85 & 0.68 to 1.07 & 0.16 \\
\hline Outpatient & 0.3 & 0.27 to 0.34 & $<0.0001$ \\
\hline Home health agency & 0.22 & 0.11 to 0.45 & $<0.0001$ \\
\hline Skilled nursing facility & 0.5 & 0.38 to 0.66 & $<0.0001$ \\
\hline Others & 0.29 & 0.26 to 0.34 & $<0.0001$ \\
\hline
\end{tabular}

DCSI, Diabetes Complications Severity Index; ESRD, end stage renal disease; $P A D$, peripheral artery disease; $Q$, quartile.

access to medical care. Our study demonstrates that racial disparity existed and is independently associated with the risk of amputation among Medicare beneficiaries insured by fee-for-service plans, even after adjusting for all the potential sociodemographic and health status confounders.
DFUs and DFIs are associated with significant healthcare utilization. ${ }^{14}$ In this study, patients who had major amputations required more outpatient visits, ED visits, and hospital admissions compared with those without major amputations. Minority beneficiaries with DFUs/ DFIs had significantly higher numbers of outpatient visits, ED visits, and inpatient hospital stays compared with white beneficiaries. Where the patient first presented for care also had a significant implication on the risks for major amputation. Beneficiaries whose DFUs/DFIs were diagnosed by a PCP or podiatrist were associated with a lower risk of amputation than those who were diagnosed by specialists. Similarly, the risk of major amputation for lower extremities was substantially lower when the diagnosis was made in an outpatient setting and not during hospital admission. It is unclear the exact reason for this observation. Potential explanations might be the more severe disease on presentation requiring hospital admission, where patients are more likely to see a specialist and not their primary care providers or podiatrists. It is also possible that the primary care providers were not comfortable with treating diabetic foot problems and patients were sent to see a specialist for diagnosis and treatment.

There are several limitations in our study. First, this is an observational study using administrative claims data. Although we tried to control for potential confounders, we do not have sociobehavioral and clinical information, such as diet and HbA1C level, and we cannot rule out unmeasured confounders. Second, there is a lack of information on the severity of the presentation, including the size of the ulcer, the severity of the infection, as well as the extent of arterial insufficiency. We also do not have information on the history of previously healed ulcers. These factors, including the severity of PAD, are likely important in evaluating major amputation risk. However, we attempted to adjust for diabetes severity as a proxy of disease severity. Third, we relied on the race/ethnicity information documented in the Medicare administrative data, and such information can vary by racial and ethnic groups. ${ }^{38}$ Fourth, we could not determine insurance status prior to the start of Medicare coverage due to the limitation of the dataset. Finally, the findings derived from the fee-for-service Medicare beneficiaries may not be generalizable to individuals enrolled in Medicare Advantage plans or other populations (eg, government sponsored Medicaid).

AAs and NAs with DFUs and DFIs were associated with an increased risk of major amputation of lower extremities compared with white Medicare beneficiaries. Race/ ethnicity, the severity of presentation (including foot infection), and the location of the initial care of the diabetic foot problems independently affect the risk of major amputation. There are racial and ethnic disparities in diabetes-related amputation and access to care for DFUs/DFIs among Medicare beneficiaries. An improve access to a PCP or podiatrist to care for DFUs/DFIs would help to address the disparities for amputation among the racial/ethnic minorities. 
Author affiliations

${ }^{1}$ University of Arizona Health Sciences Center, Tucson, Arizona, USA

${ }^{2}$ Surgery, University of Southern California, Los Angeles, California, USA

${ }^{3}$ Surgery, University of Washington School of Medicine, Seattle, Washington, USA

${ }^{4}$ Pharmaceutical Outcomes and Policy, College of Pharmacy, University of Florida Health, Gainesville, Florida, USA

Contributors T-WT, DGA, KCC-M, C-YC, DGM, WZ, EC, and W-HLC were involved in study concept and design. TT and WL were involved in the acquisition of the data. T-WT, C-YC, and W-HLC had access to the data and performed statistical analysis. All the authors interpreted the results and were involved in writing and revising the manuscript. T-WT and W-HLC had full access to the data in the study and had final responsibility for the decision to submit for publication.

Funding T-WT was supported by National Institutes of Health/National Institute of Diabetes and Kidney Disease (NIDDK) K23 Career Development Award (K23DK122126).

Competing interests None declared.

Patient consent for publication Not required.

Ethics approval The study was approved by the University of Arizona Institutional Review Board (1606628218).

Provenance and peer review Not commissioned; externally peer reviewed.

Data availability statement Data may be obtained from a third party and are not publicly available. The Medicare administrative claim data of a $5 \%$ national representative sample is available at the Medicare Coverage Database (CMS.gov)

Open access This is an open access article distributed in accordance with the Creative Commons Attribution Non Commercial (CC BY-NC 4.0) license, which permits others to distribute, remix, adapt, build upon this work non-commercially, and license their derivative works on different terms, provided the original work is properly cited, appropriate credit is given, any changes made indicated, and the use is non-commercial. See: http://creativecommons.org/licenses/by-nc/4.0/.

ORCID iD

Tze-Woei Tan http://orcid.org/0000-0002-6658-9482

\section{REFERENCES}

1 American Diabetes Association. Economic costs of diabetes in the U.S. in 2017. Diabetes Care 2018;41:917-28.

2 Boyle JP, Thompson TJ, Gregg EW, et al. Projection of the year 2050 burden of diabetes in the US adult population: dynamic modeling of incidence, mortality, and prediabetes prevalence. Popul Health Metr 2010;8:29.

3 Armstrong DG, Boulton AJM, Bus SA. Diabetic foot ulcers and their recurrence. N Engl J Med 2017;376:2367-75.

4 Prompers L, Schaper N, Apelqvist J, et al. Prediction of outcome in individuals with diabetic foot ulcers: focus on the differences between individuals with and without peripheral arterial disease. The EURODIALE study. Diabetologia 2008;51:747-55.

5 Mayfield JA, Reiber GE, Sanders LJ, et al. Preventive foot care in people with diabetes. Diabetes Care 1998;21:2161-77.

6 Apelqvist J, Larsson J, Agardh CD. Long-term prognosis for diabetic patients with foot ulcers. J Intern Med 1993;233:485-91.

7 Boyko EJ, Ahroni JH, Smith DG, et al. Increased mortality associated with diabetic foot ulcer. Diabet Med 1996;13:967-72.

8 Moulik PK, Mtonga R, Gill GV. Amputation and mortality in newonset diabetic foot ulcers stratified by etiology. Diabetes Care 2003;26:491-4.

9 Tentolouris N, Al-Sabbagh S, Walker MG, et al. Mortality in diabetic and nondiabetic patients after amputations performed from 1990 to 1995: a 5-year follow-up study. Diabetes Care 2004;27:1598-604.

10 Hoffstad O, Mitra N, Walsh J, et al. Diabetes, lower-extremity amputation, and death. Diabetes Care 2015;38:1852-7.

11 Margolis DJ, Malay DS, Hoffstad OJ, et al. Incidence of diabetic foot ulcer and lower extremity amputation among Medicare beneficiaries, 2006 to 2008: Data Points \#2. Rockville, MD: Data Points Publication Series, 2011.

12 Margolis DJ, Malay DS, Hoffstad OJ, et al. Prevalence of diabetes, diabetic foot ulcer, and lower extremity amputation among Medicare beneficiaries, 2006 to 2008: Data Points \#1. Rockville, MD: Data Points Publication Series, 2011.
13 Goldberg JB, Goodney PP, Cronenwett JL, et al. The effect of risk and race on lower extremity amputations among Medicare diabetic patients. J Vasc Surg 2012;56:1663-8.

14 Skrepnek GH, Mills JL, Lavery LA, et al. Health care service and outcomes among an estimated 6.7 million ambulatory care diabetic foot cases in the U.S. Diabetes Care 2017;40:936-42.

15 McBean AM, Gornick M. Differences by race in the rates of procedures performed in hospitals for Medicare beneficiaries. Health Care Financ Rev 1994;15:77-90.

16 Lefebvre KM, Lavery LA. Disparities in amputations in minorities. Clin Orthop Relat Res 2011;469:1941-50.

17 Lavery LA, Ashry HR, van Houtum W, et al. Variation in the incidence and proportion of diabetes-related amputations in minorities. Diabetes Care 1996;19:48-52.

18 Resnick HE, Valsania P, Phillips CL. Diabetes mellitus and nontraumatic lower extremity amputation in black and white Americans: the National health and nutrition examination survey epidemiologic follow-up study, 1971-1992. Arch Intern Med 1999;159:2470-5.

19 Feinglass J, Rucker-Whitaker C, Lindquist L, et al. Racial differences in primary and repeat lower extremity amputation: results from a multihospital study. J Vasc Surg 2005;41:823-9.

20 Young BA, Maynard C, Reiber G, et al. Effects of ethnicity and nephropathy on lower-extremity amputation risk among diabetic veterans. Diabetes Care 2003;26:495-501.

21 Eggers PW, Gohdes D, Pugh J. Nontraumatic lower extremity amputations in the Medicare end-stage renal disease population. Kidney Int 1999:56:1524-33.

22 Karter AJ, Ferrara A, Liu JY, et al. Ethnic disparities in diabetic complications in an insured population. JAMA 2002;287:2519-27.

23 Eslami MH, Zayaruzny M, Fitzgerald GA. The adverse effects of race, insurance status, and low income on the rate of amputation in patients presenting with lower extremity ischemia. $J$ Vasc Surg 2007:45:55-9.

24 Blumberg SN, Warren SM. Disparities in initial presentation and treatment outcomes of diabetic foot ulcers in a public, private, and Veterans administration Hospital. J Diabetes 2014;6:68-75.

25 Loehrer AP, Hawkins AT, Auchincloss HG, et al. Impact of expanded insurance coverage on racial disparities in vascular disease: insights from Massachusetts. Ann Surg 2016;263:705-11.

26 Henry AJ, Hevelone ND, Belkin M, et al. Socioeconomic and hospital-related predictors of amputation for critical limb ischemia. $J$ Vasc Surg 2011;53:e331:330-9.

27 Cohen MS, Weisskoff RM. Ultra-fast imaging. Magn Reson Imaging 1991;9:1-37.

28 Sohn M-W, Budiman-Mak E, Stuck RM, et al. Diagnostic accuracy of existing methods for identifying diabetic foot ulcers from inpatient and outpatient datasets. J Foot Ankle Res 2010;3:27.

29 Tan T-W, Shih C-D, Concha-Moore KC, et al. Disparities in outcomes of patients admitted with diabetic foot infections. PLoS One 2019;14:e0211481.

30 Elixhauser A, Steiner C, Harris DR, et al. Comorbidity measures for use with administrative data. Med Care 1998;36:8-27.

31 Chang $\mathrm{H}-\mathrm{Y}$, Weiner JP, Richards TM, et al. Validating the adapted diabetes complications severity index in claims data. Am J Manag Care 2012;18:721-6.

32 Chang $\mathrm{H}-\mathrm{Y}$, Weiner JP, Richards TM, et al. Predicting costs with diabetes complications severity index in claims data. Am J Manag Care 2012;18:213-9.

33 Rivero M, Nader ND, Blochle R, et al. Poorer limb salvage in African American men with chronic limb ischemia is due to advanced clinical stage and higher anatomic complexity at presentation. J Vasc Surg 2016;63:1318-24.

34 Mills JL, Conte MS, Armstrong DG, et al. The Society for vascular surgery lower extremity threatened limb classification system: risk stratification based on wound, ischemia, and foot infection (WIfl). $J$ Vasc Surg 2014;59:220-34. e221-2.

35 Ndosi M, Wright-Hughes A, Brown S, et al. Prognosis of the infected diabetic foot ulcer: a 12-month prospective observational study. Diabet Med 2018:35:78-88.

36 Hughes K, Mota L, Nunez M, et al. The effect of income and insurance on the likelihood of major leg amputation. $J$ Vasc Surg 2019:70:580-7.

37 Flavin NE, Mulla ZD, Bonilla-Navarrete A, et al. Health insurance and the development of diabetic complications. South Med J 2009;102:805-9.

38 Filice CE, Joynt KE. Examining race and ethnicity information in Medicare administrative data. Med Care 2017;55:e170-6. 